\title{
Identified Motoneurons and Their Innervation of Axial Muscles in the Zebrafish
}

\author{
Monte Westerfield, James V. McMurray, and Judith S. Eisen \\ The Institute of Neuroscience, University of Oregon, Eugene, Oregon 97403
}

The organization of spinal cord motoneurons and their innervation of axial (white) muscles in the zebrafish were studied. Motoneurons can be divided into 2 classes, primary and secondary, on the basis of their cell-body sizes and positions. Each side of each spinal segment contains 3 primary motoneurons that are uniquely identifiable as individuals by their stereotyped cell-body positions and peripheral branching patterns. Moreover, these motoneurons precisely innervate cell-specific subsets of contiguous muscle fibers in mutually exclusive regions of their own body segment. Individual muscle fibers receive inputs from a single primary motoneuron and, in addition, from up to 3 secondary motoneurons. The results demonstrate that the precision of innervation previously described in invertebrates is also present in some vertebrates.

The skeletal muscles of vertebrates are innervated by anatomically discrete groupings of motoneurons, or motoneuron pools, that occur in characteristic locations within the spinal cord (Landmesser, 1980). The neurons of a given pool innervate a particular muscle in a precise manner that is highly reproducible in different individuals. Does this precision extend to the level of individual neurons within the pool?

Most previous studies have failed to demonstrate that individual motoneurons specifically innervate particular subsets of muscle fibers spatially localized within a muscle. The majority of muscles are composed of a mixture of muscle fiber types that can be distinguished on the basis of size, speed and force of contraction, and enzyme composition (Hoyle, 1983). The fibers innervated by a single motoneuron (together with the motoneuron termed the motor unit) are usually of one type (Burke et al., 1973), but different motor units can vary considerably in the number and distribution of fibers within the muscle. The dispersion of muscle fibers within motor units may be functionally significant (Willison, 1980).

Individual neurons that can be uniquely identified in different members of a species have been extremely useful for a wide variety of neurobiological studies. Such identified neurons have been found primarily in invertebrates. Notable exceptions include uniquely identifiable reticulospinal neurons like the Mauthner cell in lamprey (Rovainen, 1978) and in larval zebrafish (Kimmel, 1982; Metcalfe et al., 1985). We report here the characterization of individual, identified motoneurons in the spinal cord of juvenile and adult zebrafish. We show that these neurons, which are present as single cells on each side of each spinal segment, have unique and reproducible central locations and peripheral branching patterns. Moreover, each mo-

\footnotetext{
Received Oct. 22, 1985; revised Jan. 10, 1986; accepted Jan. 13, 1986.

We wish to thank Paul Myers and Charles Kimmel for helpful discussions and Harrison Howard and David Brumbley for technical assistance. Supported by the NIH NS21 132 and NS17963, the Muscular Dystrophy Association, and the Medical Research Foundation of Oregon. M.W. was an Alfred P. Sloan Fellow.

Correspondence should be addressed to Monte Westerfield at the above address.

Copyright (c) 1986 Society for Neuroscience 0270-6474/86/082267-1 1\$02.00/0
}

toneuron precisely innervates a cell-specific subset of contiguous muscle fibers within its own segment. In the following paper we describe the initial axonal outgrowth, pathway selection, and innervation patterns of these same motoneurons identified in embryonic zebrafish. We show that each of these neurons follows a cell-specific, stereotyped pattern of development and from axogenesis establishes projections appropriate for its adult function. Some of these results have been described previously (Westerfield et al., 1984).

\section{Materials and Methods}

\section{Animals}

Larval and adult zebrafish were obtained from a laboratory colony. Animals were maintained at $28.5^{\circ} \mathrm{C}$ on a $14 \mathrm{hr}$ light/10 hr dark cycle. They were raised in $250 \mathrm{ml}$ beakers, 25 animals per beaker, for 3 weeks and were then transferred to 10 gallon aquaria with 15-25 animals per aquarium. Animals were fed paramecia during the first 2 weeks of development, newly hatched brine shrimp from 2 weeks to a month, and adult-type fish flake food after a month. Animals as young as $5 \mathrm{~d}$ and as old as 2 years were included in the present study.

\section{Observation of gross anatomy}

Fish were anesthetized by immersion in $0.03 \%$ tricaine at $\mathrm{pH} 7.2$. Anesthesia was maintained by placing the fish on a cold plate at $5^{\circ} \mathrm{C}$. The animal was decapitated and eviscerated, the skin was removed, and one side of the animal was cut away, leaving the spinal cord, vertebral column and muscles on the contralateral side. This study was confined to segments 8-15. The preparation was then transferred to a chamber whose bottom was made from a glass coverslip. The preparation was immersed in oxygenated physiological saline with the following composition: $\mathrm{NaCl}, 116 \mathrm{~mm} ; \mathrm{KCl}, 2.0 \mathrm{~mm} ; \mathrm{CaCl}_{2}, 1.8 \mathrm{~mm}$; glucose, $15 \mathrm{~mm}$; HEPES, $5 \mathrm{~mm}$, buffered to $\mathrm{pH} 7.2$ and bubbled with $100 \% \mathrm{O}_{2}$. Observations were made with a dissecting microscope or with a compound microscope using a $10 \times$ objective. In some cases, nerves and muscles were stained with methylene blue or neutral red to aid in their visualization.

\section{Physiological recording}

Animals were prepared as above and placed in a recording chamber containing physiological saline with the $\mathrm{CaCl}_{2}$ concentration lowered to $0.9 \mathrm{~mm}$ to reduce muscle contractions. The chamber was continuously perfused with fresh oxygenated saline and was maintained at $14^{\circ} \mathrm{C}$. Nerves were stimulated with en passant suction electrodes near the ventral root or by threading a Teflon-coated platinum wire down the spinal cord to the level of the ventral root. Glass micropipettes (20-40 $\mathrm{M} \Omega$ filled with $3 \mathrm{M} \mathrm{KCl}$ ) were used for stimulation and recording from muscle fibers and axons. For penetration, axons were visualized with a water-immersion lens ( $40 \times$ Neofluor, Zeiss). In experiments that required intracellular stimulation of the axons, the preparation was treated briefly (5-10 $\mathrm{min}$ ) with $3 \mathrm{M}$ formamide to reduce muscle contractions further (del Castillo and Escalona de Motta, 1978). Muscle fibers with resting potentiais less than $-60 \mathrm{mV}$ and axons with resting potentials lcss than $-40 \mathrm{mV}$ were excluded from the study. Average values are calculated $\pm 1 \mathrm{SD}$.

The number of discrete steps in the end plate potential (EPP) in response to graded stimulation of the nerve was taken as a measure of 
Figure 1. Organization of muscles and nerves. Top, Drawing of an adult zebrafish, $3 \mathrm{~cm}$ in length, showing the segmental organization of the body. sagittal view with the same orientation as in the top panel. The spinal cord $(s c)$ and vertebral column $(v)$ are indicated. Segments are separated by myosepta $(\mathrm{ms})$, and the dorsal and ventral muscles in each segment are separated by the horizontal septum (hs). The myosepta extend caudally and tilt in the dorsal part of the segment (Romer, 1962); their most medial profiles are shown in the diagram. This tilting makes the dorsal nerve $(d n)$ appear to project caudal to the septum, in the diagram, although the nerve actually remains in the center of the segment as the segment extends caudally and laterally. For clarity, only the most medial axonal branches are shown. The ventral nerve $(v n)$ gives rise to a lateral branch (not shown) dorsal of the $h s$ and septal $(s b)$ and median $(\mathrm{mb})$ branches ventral of the $h s$, Side branches are observed ventral to the septum. The $s b$ courses rostrally to the myoseptum and then turns tral rib. It supplies only a few side branches. Farther ventrally, the $s b$ often forms a small branch that crosses the septum and enters the next more rostral segment, the main trunk of the septal branch continuing ventrally along the rib. This ventral extension of the $s b$ eventually supplies branches to muscles ventral of the ribs and muscles in the fins in finned segments and a smaller median branch that continues ventrally in the middle of the segment nearly to the end of the ribs. The $m b$ supplies side branches along its length. It seldom extends below the ventral aspect of the ribs. Only the proximal parts of the nerves are shown. Scale bar, $300 \mu \mathrm{m}$ (bottom panel). Bottom, Diagram of segments $8-10$ in ventrally and runs parallel to the ros-
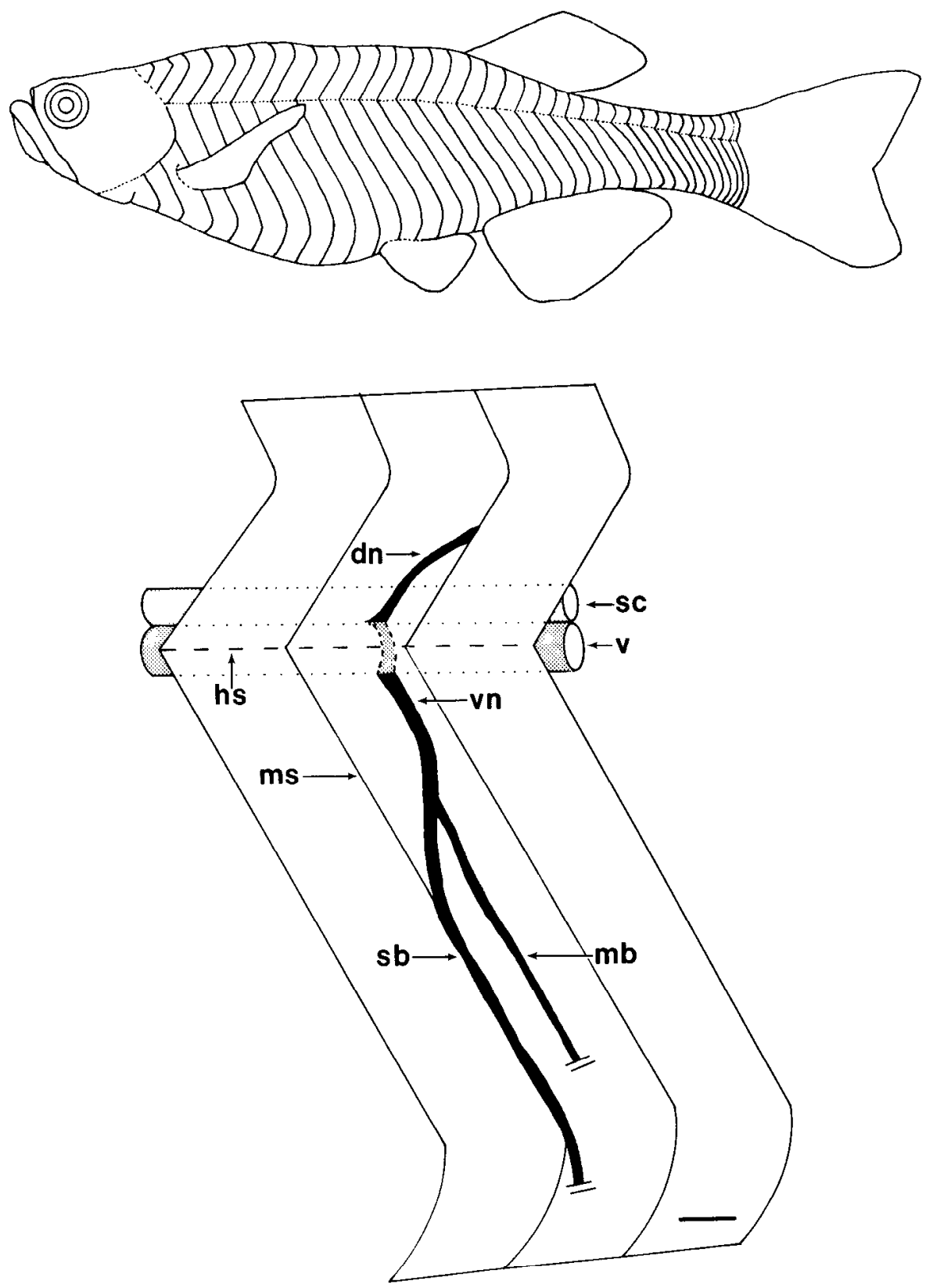

the number of motor axons innervating each muscle fiber (Lichtman, 1977). The numbers obtained with this method may represent an underestimate of the actual number of innervating axons, if the recording site is distant from the nerve terminal. This is an unlikely problem in the present study, since individual motor axons in the zebrafish establish multiple end plates distributed along the length of the muscle fibers.

\section{Intracellular dye injections}

Motoneurons were labeled by injecting their axons with HRP. Axons were visualized with the procedure outlined above. The HRP $(5 \%$ in $0.5 \mathrm{M} \mathrm{KCl}$ ) was loaded into glass micropipettes with tips that had been broken to a diameter of approximately $1 \mu \mathrm{m}$ and was injected into individual axons using 1-5 pounds of pressure. In some cxperiments, bulk labeling of axons was accomplished by cutting the spinal nerve and placing a crystal of HRP on the cut end. The preparations were then placed in an incubator at $28.5^{\circ} \mathrm{C}$ for $5 \mathrm{hr}$ to allow diffusion of the HRP throughout the labeled cells. The saline was replaced with freshly oxygenated solution every half-hour. The preparation was then processed as a whole-mount for the HRP reaction product using standard procedures (Westerfield and Eisen, 1985).

\section{Results}

\section{Organization of axial muscles and nerves}

\section{Muscle anatomy}

The axial muscles in the zebrafish, as in other teleost fishes, are segmentally arranged. Each segment, when viewed from the side, resembles the letter "W" tipped on end (Fig. 1, top panel). Adjacent segments are separated by myosepta (van Raamsdonk et al., 1974) and the ribs. The muscles on each side of each segment, or myotome, are divided into 2 regions, dorsal and ventral, by a horizontal septum (Fig. 1, bottom panel). The horizontal septum spans the segment longitudinally between adjacent ribs. It extends from the internal surface of the muscle (near the vertebrae) to the lateral surface. The bulk of the muscles are composed of white fibers. Within both the dorsal and the ventral parts of the segment, 2 layers of white muscle fibers are apparent. Muscle fibers in the superficial (more lateral) layermuscularis obliquus externus (Alexander, 1969)-are oriented 


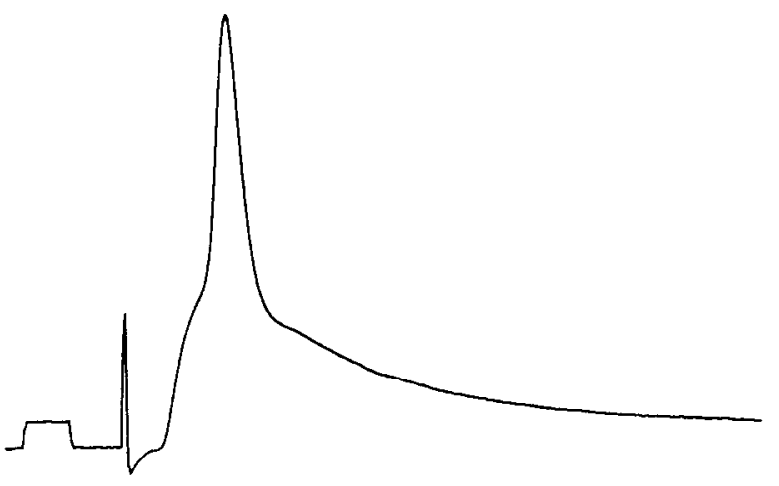

Figure 2. Nerve evoked muscle action potential. Stimulation of the ventral nerve elicited a large EPP, which produced the action potential. Normal saline, resting potential, $-87 \mathrm{mV}$. The calibration pulse at the beginning of the trace is $5 \mathrm{mV}$ and $2 \mathrm{msec}$. It is followed by the stimulus artifact.

obliquely to the long axis of the ribs, attaching farther dorsal at their rostral ends and farther ventral at their caudal ends. Fibers in the deeper (more medial) layer - muscularis obliquus internus (Alexander, 1969)-are oriented nearly perpendicular to the long axis of the ribs. Each layer is several muscle fibers thick. The red muscle is confined to a narrow region at the lateral edge of the segment, as described previously by Waterman (1969).

\section{Organization of the nerves}

The spinal nerve on each side of each segment has 2 major branches that diverge in the middle of the segment on the medial surface of the muscle. This was observed directly in intact, 1-month-old animals, which are still clear enough to see through, and in dissected, skinned adults. One branch formed the dorsal nerve (Fig. 1, bottom panel) coursing dorsally and caudally between the muscle and the vertebrae. It remained in the center of the segment (see legend to Fig. 1) and could be followed to the dorsal aspect of the muscle. Numerous small side branches could be seen. The other branch formed the ventral nerve. This nerve gave rise to 3 major branches-lateral, septal, and median. The lateral branch projected toward the lateral surface of the muscle parallel and slightly dorsal to the horizontal septum. The septal branch ran near the rostral myoseptum, and the median branch projected ventrally in the center of the segment.

\section{Excitability of muscle fibers}

Fast muscle fibers in the zebrafish are electrically excitable. Intracellular recordings from individual fibers showed that the resting potential could be as large as $-92 \mathrm{mV}$, with an average value of $-82 \pm 7 \mathrm{mV}$ (87 fibers, 5 animals). Increasing depolarization of the membrane potential by injection of current through the recording electrode first elicited graded contractions of the fibers without action potentials. A depolarization of 20 $30 \mathrm{mV}$ elicited an all-or-none action potential and a rapid twitch.

Stimulation of the spinal nerve produced activation of the muscle and a contraction. As shown in Figure 2, stimulation of the nerve produced a $20-30 \mathrm{mV}$ depolarizing EPP that led to an action potential in the muscle fiber. In most cases $(61 \%$ of 57 fibers, 2 animals), minimal stimulation of the nerve evoked muscle action potentials. Increased stimulus strengths elicited action potentials in many of the remaining fibers (see polyneuronal innervation, below). These remaining fibers with apparently higher thresholds had normal resting potentials $(-81 \pm 8$ $\mathrm{mV}, 21$ fibers).

\section{Motoneuron classes}

Previous studies in larval amphibians (Blight, 1978), developing zebrafish (Myers, 1983, 1985), and adult goldfish (Faber and Korn, 1978) have identified 2 classes of motoneurons, primary and secondary, that innervate myotomal muscles. We have observed these 2 classes in adult zebrafish (Fig. 3). The larger motoneuron of Figure $3 \mathrm{~A}$ corresponds, in size, location, and axon path to the primary motoneurons of these earlier studies, while the smaller cell (Fig. 3B) has the characteristics of a secondary motoneuron.

The somata of the larger class of motoneurons (Fig. $3 A$ ) had cross-sectional areas of $670 \pm 150 \mu \mathrm{m}$ ( 5 primary motoneurons,
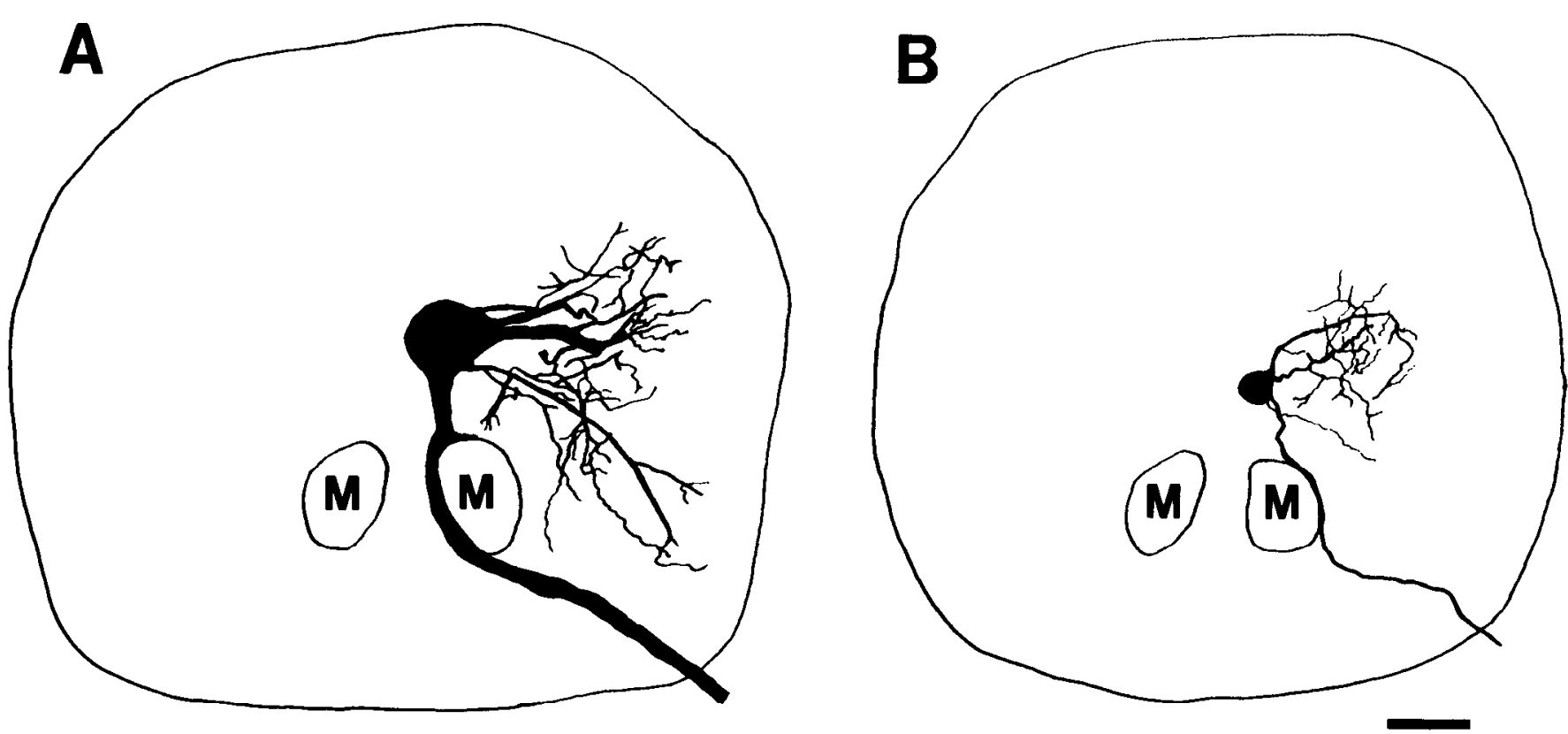

Figure 3. Two classes of motoneurons. Motoneurons were labeled by retrograde transport of HRP injected into their axons in the spinal nerve. Transverse sections from the spinal cords of 2 different animals. $A$, Primary motoneuron (CaP; see Fig. 4 ) from segment $11 . B$, Secondary motoneuron from segment 12. Its peripheral arbor is shown in Figure 5. The Mauthner axons are indicated $(M)$. Scale bar, $50 \mu \mathrm{m}$. 

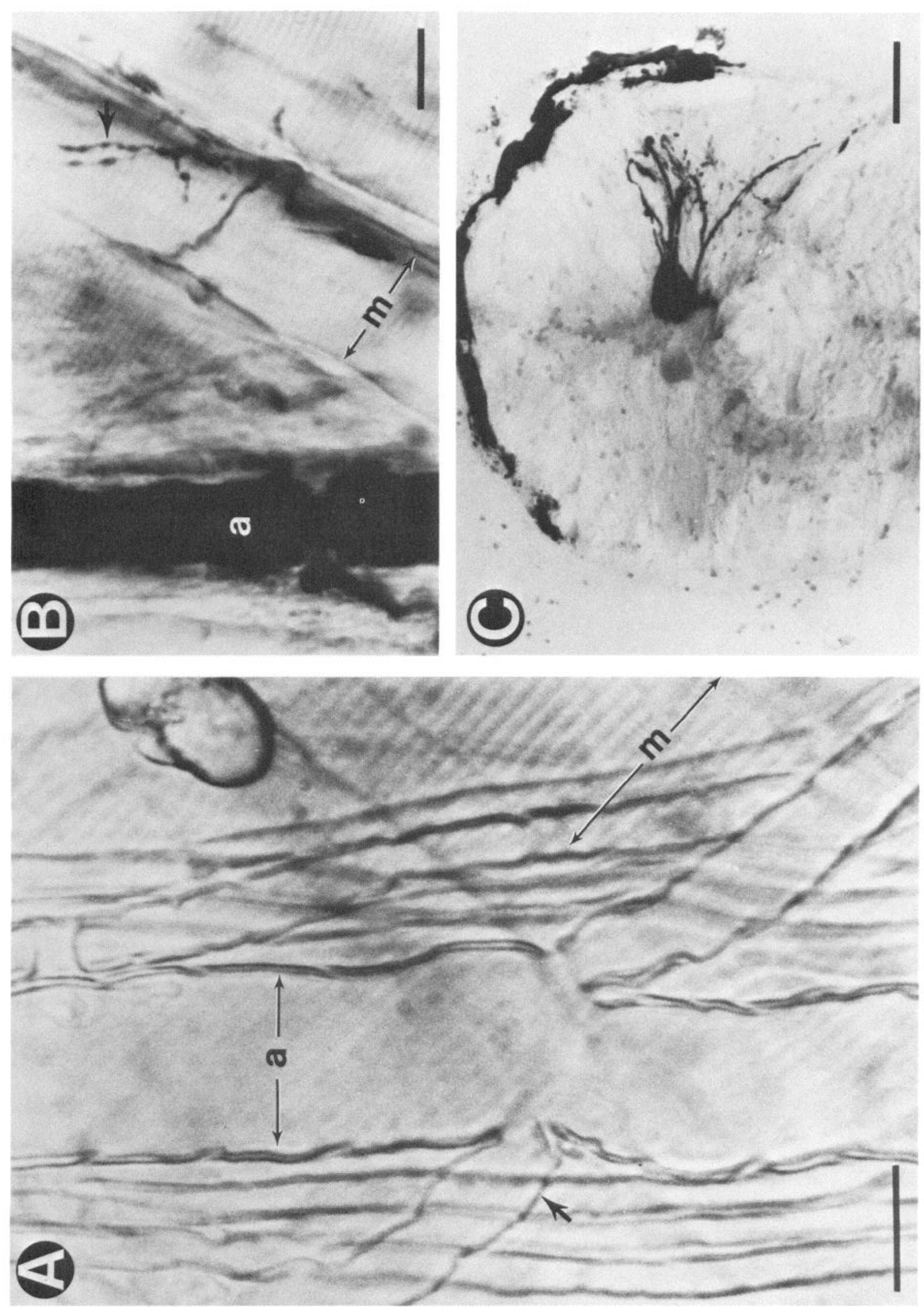

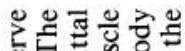

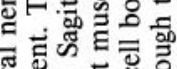

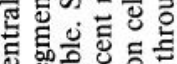

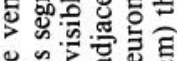

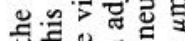
㟧. 둥

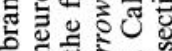
I ब 0

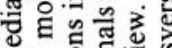
घ요의 气. ⿷匚丁 o

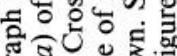
可

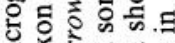

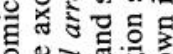

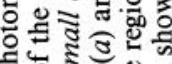
क्षे के

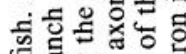

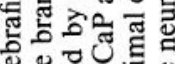
N. 월 독 वृ.

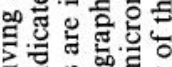
.

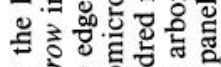

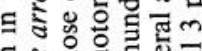

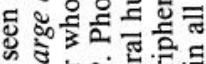

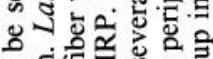

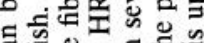

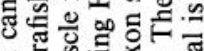
ธี

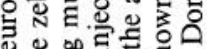

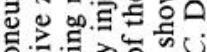
응

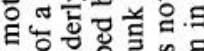
글 ฮึ: 政

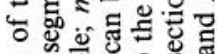
도.울 을

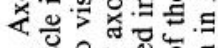
४色

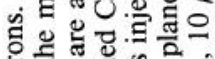

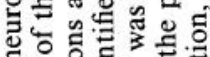

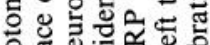
讨 壹

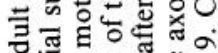

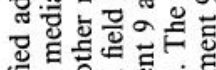

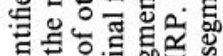
응

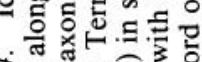

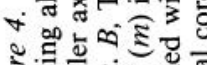

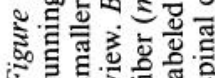




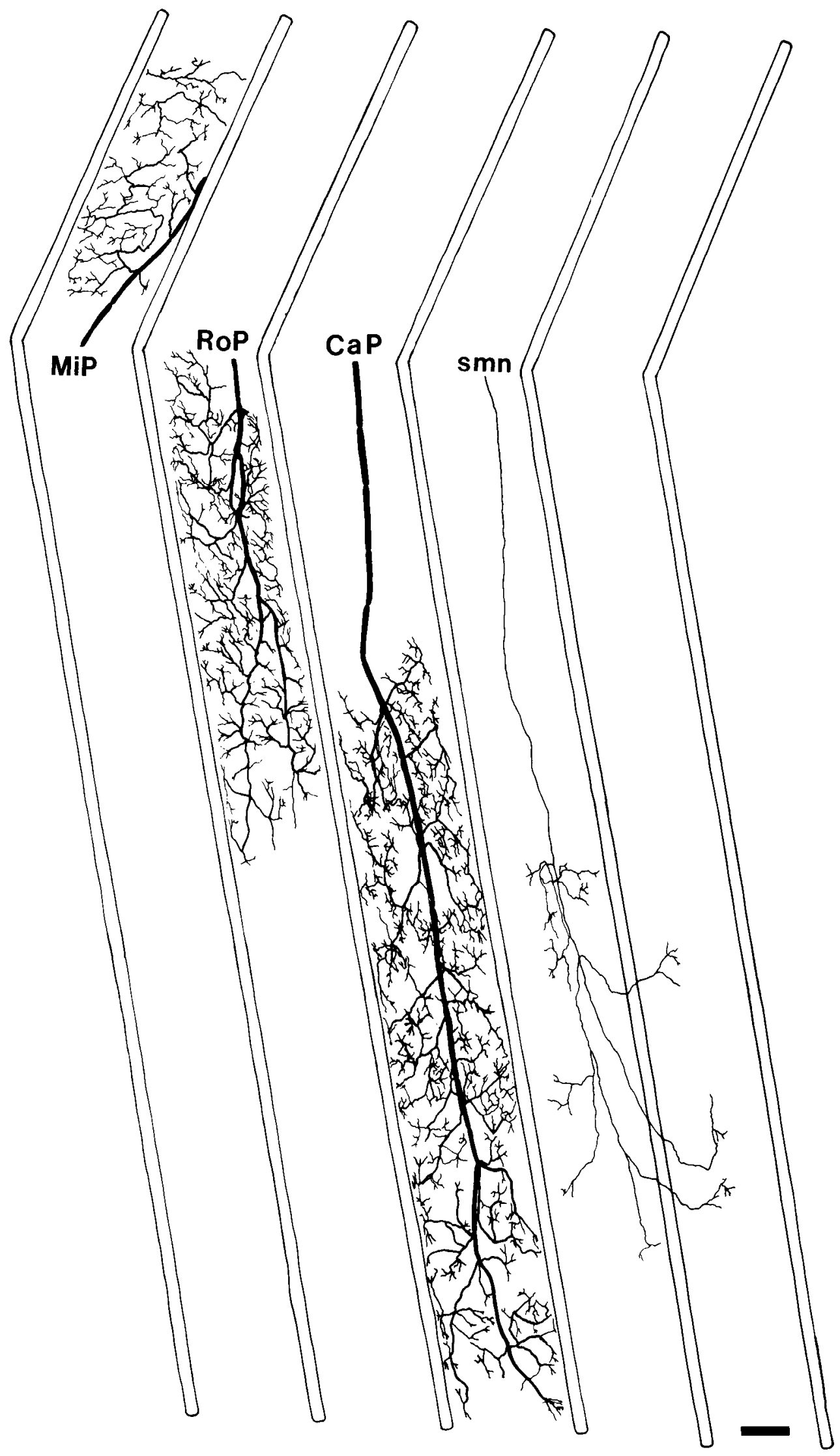

Figure 5. Motoneurons project to specific regions of the muscle. Camera lucida drawings of the peripheral arbors of 4 motoneurons drawn from whole-mounts of 4 different animals. The clear slanted bars represent the ribs; the drawings are of sagittal views, with dorsal up and rostral at left. The first segment on the left shows the projection of a MiP motoneuron in segment 12. The main trunk of the axon remains within the dorsal nerve, which passes the rib laterally as it runs caudally along the medial surface of the muscle of its segment. Only the proximal portion of the arbor is shown. The second segment illustrates the arbor of a RoP moloneuron in segment 10. The ventral part of the arbor was confined to the most lateral fibers of the muscle. The third segment illustrates a $\mathrm{CaP}$ motoneuron (the one whose cell body is shown in Fig. 4C). Only the medial projections are shown. The last two segments illustrate the peripheral arbor of the secondary motoneuron shown in Figure $3 B$. Several of its side branches crossed the myoseptum to terminate in the adjacent caudal segment. The arbor of $\mathrm{CaP}$, third segment from the left, was adjusted for distortion by moving the ventral ends of the ribs $30 \%$ closer to each other. Calibration, $300 \mu \mathrm{m}$. 


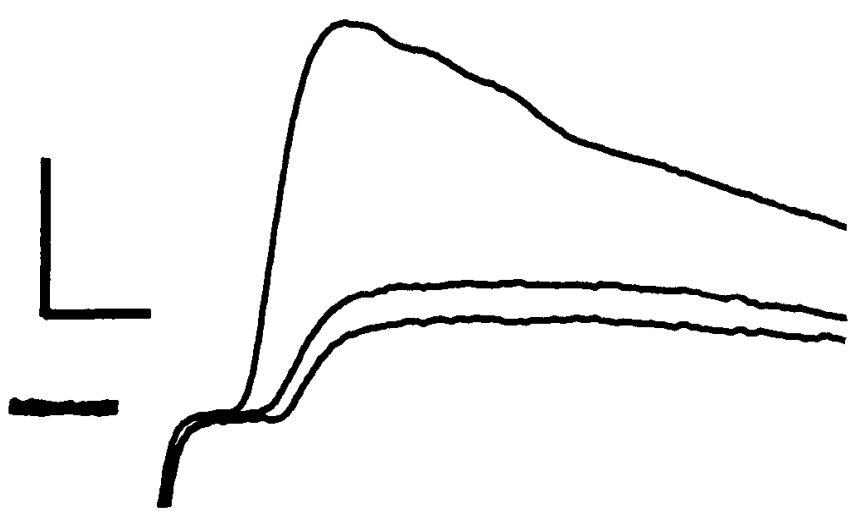

Figure 6. Polyneuronal innervation. A muscle fiber that received input from 3 separate motor axons. EPPs were elicited at different, discrete thresholds by increasing the strength of the stimulus applied to the ventral root. Low-calcium saline containing $0.9 \mathrm{mM} \mathrm{Ca}^{2+}$; resting potential, $-83 \mathrm{mV}$; calibration, $2 \mathrm{mV}$ for lower 2 traces, $5 \mathrm{mV}$ for top trace, and $2 \mathrm{msec}$ for all 3 traces. Stimulus artifacts have been retouched for clarity.

5 animals). They were consistently located in a relatively central position within the cross section of the spinal cord. Their large axons coursed ventrally from their cell bodies and made conspicuous loops around the medial surface of the Mauthner axon before entering the ventral root. The other class of motoneurons (Fig. $3 B)$ had smaller somata $(169 \pm 60 \mu \mathrm{m} ; 5$ motoneurons, 4 animals). They were located more ventrally and laterally, and their smaller axons coursed lateral to the Mauthner axon in their path to the ventral root. In most cases there was no obvious contact between the axons of the secondary motoneurons and the Mauthner axon at the light-microscopic level. The dendrites of secondary motoneurons appeared to overlap with those of the primary motoneurons, although they were less extensive. The motoneuron shown in Figure $3 B$ is an extreme example of a secondary motoneuron that was more like a primary in its dorsal, medial soma position and the close apposition between its axon and the Mauthner axon.

\section{Identified motoneurons}

The muscles on either side of each body segment of the zebrafish are innervated by 3 individually identified primary motoneurons. These motoneurons are recognizable as individuals from animal to animal based on their consistent morphology. We have uniquely identified each cell by its axonal pathway and soma position and have named them according to their longitudinal positions within the spinal cord: RoP (rostral primary), MiP (middle primary), and $\mathrm{CaP}$ (caudal primary).

\section{Uniquely identifiable axons in the peripheral nerves}

The individual axons of these 3 primary motoneurons are identifiablc in the peripheral nerves by direct observation of the nerves in living, skinned preparations of larvae and adults. The median branch of the ventral nerve (Fig. $4 A$ ) consistently contained the single large (ca. $15 \mu \mathrm{m}$ diameter) axon of the $\mathrm{CaP}$ motoneuron ( 40 out of 40 segments observed with bright-field optics in 4 animals) and about 6 smaller axons. The CaP axon could be followed from its emergence from the ventral root to its distal ends near the ventral tips of the ribs. At intervals along its length it gave off side branches (Fig. $4 A$ ) and decreased in diameter distal to the branch points.

The identifiable axon of the RoP motoneuron was also found in the ventral nerve. It could be visualized emerging from the ventral root and entering the ventral nerve. As this axon projected ventrally past the horizontal septum, it left the ventral nerve and dove deeply into the muscle to supply branches to

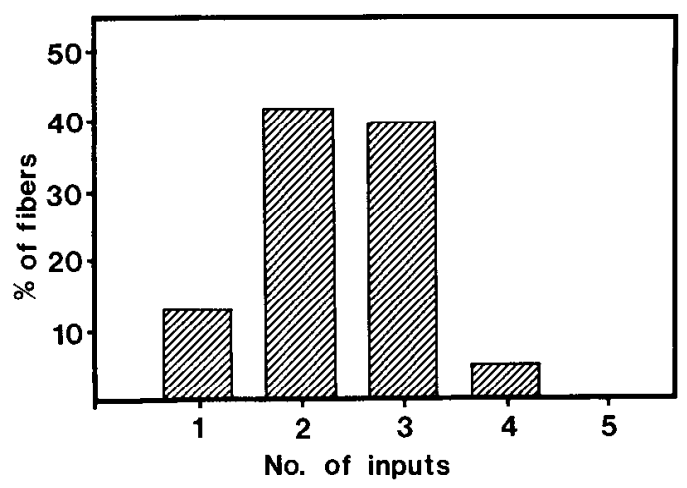

Figure 7. Most fibers are polyneuronally innervated. Histogram of percentage of fibers (170 fibers, 14 animals) that received EPPs from a given number of motor axons (No. of inputs).

the dorsal part of the ventral muscle. The third large identifiable axon, MiP, was consistently found in the dorsal nerve. This axon remained in the main trunk of the dorsal nerve and supplied branches at regular intervals along its length. None of the other major nerve branches, including the septal branch, contained axons of the primary motoneurons. Counts of the total number of axons in histological sections of the ventral roots showed that there was a small and reproducible number of axons (71 \pm 8 axons, 8 ventral roots, 3 animals) in trunk segments without fins. The 3 axons of the primary motoneurons could be recognized by their large size at the level of the ventral root in these sections.

\section{Uniquely identifiable primary motoneurons}

These 3 large axons, recognizable in the nerves, are the peripheral processes of the primary motoneurons. This was determined by injection of HRP into individual axons to orthogradely label their terminals on the muscles (Fig. $4 B$ ) and retrogradely label their cell bodies in the spinal cord (Fig. 4C). Injection of the large axon in the median branch of the ventral nerve always ( 5 injections, 5 animals) labeled the $\mathrm{CaP}$ motoneuron. Its cell body was reproducibly located in the middle of the spinal segment near or slightly rostral to the ventral root. Injection of the second large axon in the ventral nerve labeled the RoP motoneuron consistently ( 6 axons, 4 animals). Its cell body was located rostral to the ventral root, $42 \pm 10 \%$ (5 animals) of the distance to the next root. Injection of the large axon in the dorsal nerve consistently ( 8 axons, 8 animals) labeled the MiP motoneuron whose soma position was intermediate between the 2 ventrally projecting cells, $28 \pm 6 \%$ ( 3 animals) of the distance to the next more rostral root.

These 3 adult primary motoneurons corresponded in positions and morphologies to the primary motoneurons we have also found in embryonic (Eisen et al., 1986) and larval (Myers et al., 1985) zebrafish. Their cell bodies occupied a relatively dorsal and medial position within the cross section of the spinal cord (Fig. 3A). Their dendrites projected extensively into a neuropil region lateral to their cell bodies, and their axons made a conspicuous loop around the medial aspect of the Mauthner axon before leaving the spinal cord in the ventral root.

\section{Terminal fields}

\section{Primary motoneuron axonal arbors}

The 3 primary motoneurons have nonoverlapping arbors in mutually exclusive regions of the muscle within their own segment (Fig. 5). The arbor of each axon was confined to its own segment and to a particular region of its segment. The axons branched extensively and appeared to make terminals on many 

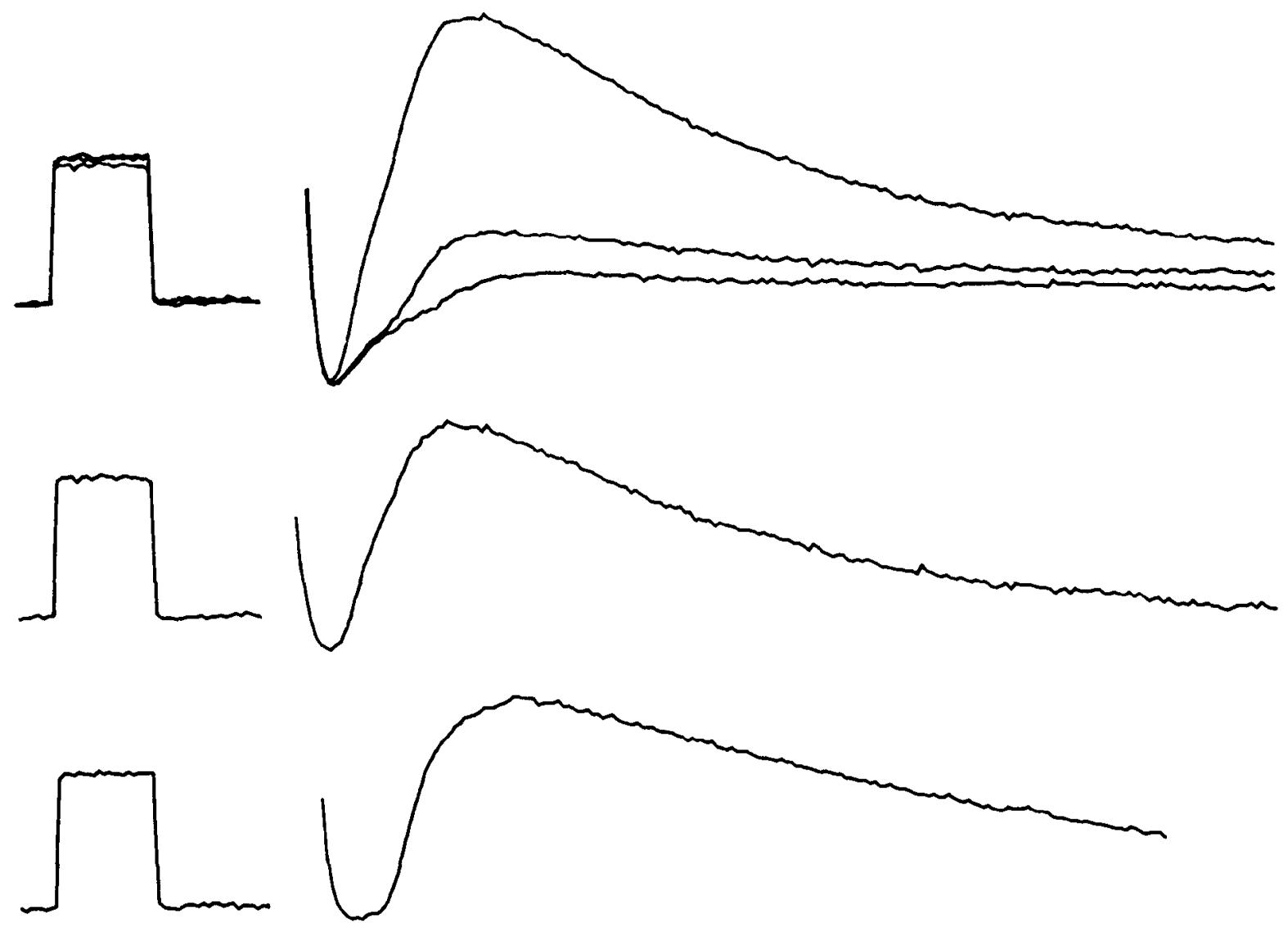

Figure 8. Primary motoneurons make shorter latency EPPs. Intracellular recordings from a muscle fiber in the ventral part of segment 12 that received inputs from 3 motoneurons. Upper panel, Graded stimulation of the ventral root elicited EPPs with 3 discrete amplitudes (0.9, 2.6, and $10.1 \mathrm{mV})$. The largest EPP appeared with the shortest latency $(1.8 \mathrm{msec})$. Middle panel, EPP generated by the shortest latency axon. The amplitude of the short-latency EPP $(7.3 \mathrm{mV})$ by itself was calculated by subtracting the sum of the 2 smaller EPPs (middle trace in upper panel) from the composite EPP (top trace in upper panel). Lower panel, EPP elicited by intracellular stimulation of the CaP axon. Its amplitude (6.9 $\mathrm{mV}$ ) corresponded to the EPP generated by the axon with the shortest latency stimulated in the ventral root (middle panel). The latency of this EPP was somewhat longer due to the delay caused by stimulating through the microelectrode. Resting potential of muscle fiber, $-83 \mathrm{mV}$; resting potential of CaP axon, $-63 \mathrm{mV}$; calibration, $5 \mathrm{mV}$ and $2 \mathrm{msec}$. The preparation had been treated with $3 \mathrm{M}$ formamide for 6 min before recording. Stimulus artifacts have been retouched for clarity.

or all the muscle fibers within its region. Each axon contacted an individual muscle fiber at multiple sites distributed along the length of the fiber. Thus, the muscle fibers are multiterminally innervated.

The field of each primary motoneuron was unique. The MiP axon, in the dorsal nerve, had an extensive arbor that covered most of the dorsal muscle of its own segment (Fig. 5, left segment). None of its branches was observed to cross segment boundaries or the horizontal septum (6 axons, 4 animals). Its branches extended from the main trunk of the nerve across the medial surface of the muscle and through to the lateral surface. Only the dorsal muscle fibers nearest the horizontal septum (a region innervated by RoP, see below) appeared to be devoid of terminals from the MiP axon.

The RoP axon, in the ventral nerve, projected exclusively to muscle fibers in the dorsal part (the dorsal $42 \pm 2 \%$ of the region between the spinal cord and the ventral ends of the ribs; 5 axons, 4 animals) of the ventral muscle (Fig. 5, second segment). In the dorsal part of this region, branches extended from the medial surface through the muscle to the lateral surface. Further ventrally, the main trunk of this axon passed from medial to lateral, such that its most ventral projections were confined to the lateral layers of muscle fibers.

The CaP axon, in the median branch of the ventral nerve, had the largest and most extensive branching pattern (Fig. 5,

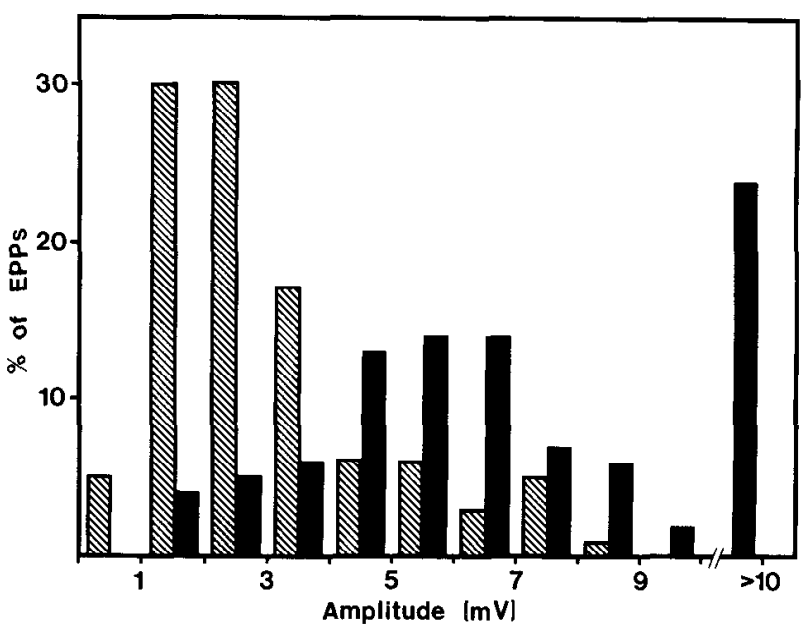

Figure 9. Primary motoneurons make larger EPPs. Amplitude histogram of the percentage of EPPs recorded in the ventral muscle with a given amplitude for short latency $(<2.1 \mathrm{msec}$, black bars) and longer latency (>2.1 msec, cross-hatched bars) inputs. The short-latency EPPs correspond to inputs from primary motoneurons (82 EPPs, 10 animals), while the longer latency EPPs are generated by secondary motoneurons (116 EPPs, 10 animals). 

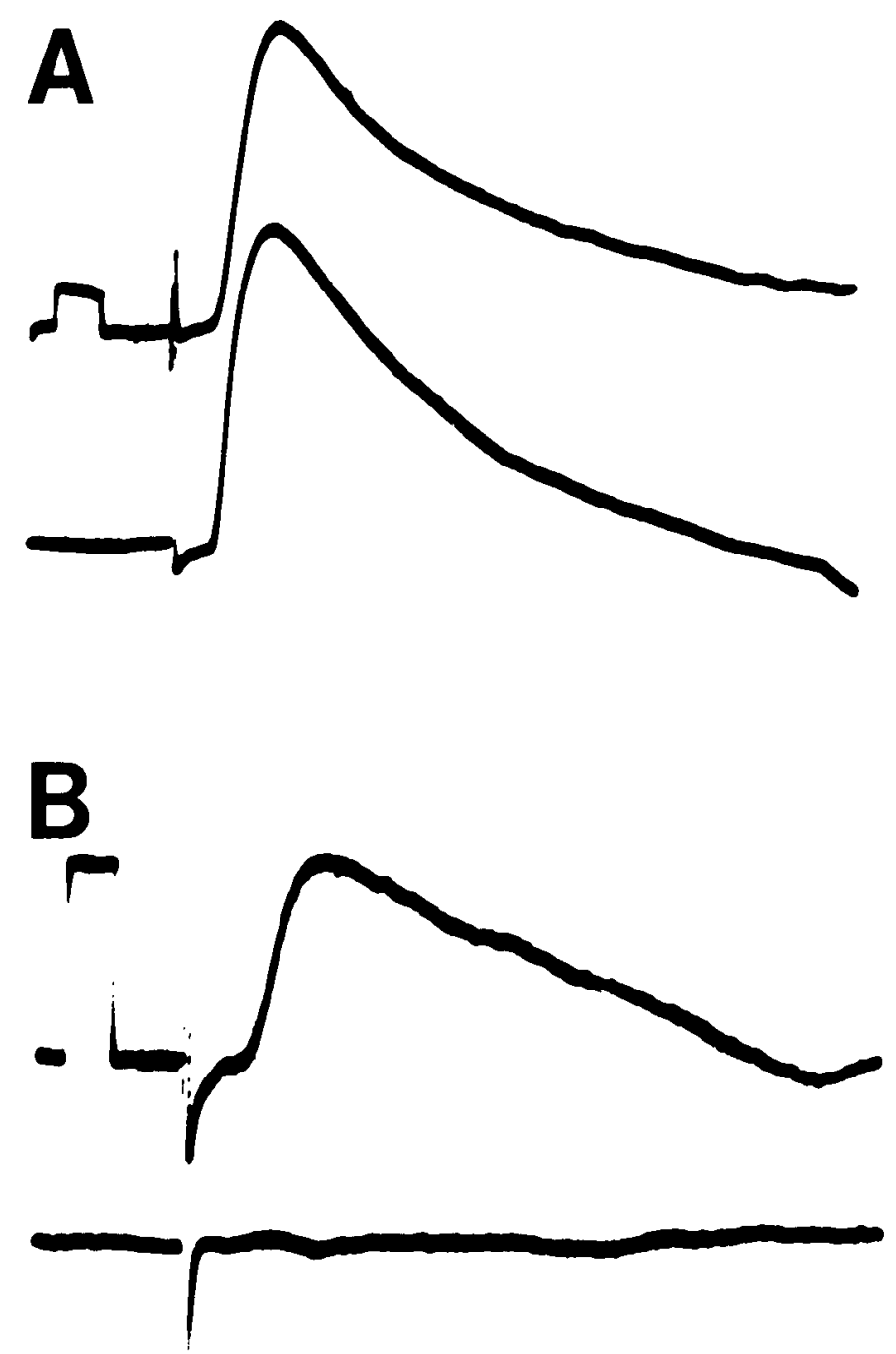

Figure 10. Primary motoneurons innervate many of the fibers within thcir own region. Simultaneous recordings from 2 pairs of muscle fibers. EPPs from individual motor axons were identified by varying the stimulus strength and determining which EPPs in the 2 fibers had the same threshold. Examples from 2 different animals are shown. $A$, Single motor axon innervated 2 different fibers within its field in the ventral muscle. It was classified as a primary motor axon by the large amplitudes (12 and $10.5 \mathrm{mV}$ ) and short latencies (1.8 and $1.7 \mathrm{msec}$, upper and lower traces, respectively) of its EPPs. $B$, Motor axon innervated a fiber within its field in the ventral muscle (upper trace) but failed to project to a fiber outside its field (lower trace). It was classified as a secondary motor axon by the small amplitude $(1.9 \mathrm{mV})$ and long latency $(2.8 \mathrm{msec})$ of its EPP. Resting potentials: $A,-85 \mathrm{mV}$, upper trace, $-75 \mathrm{mV}$, lower trace; $B,-90 \mathrm{mV}$, upper trace, $-82 \mathrm{mV}$, lower trace. Calibration pulses, $2 \mathrm{mV}$ and $2 \mathrm{msec}$.

third segment). The first branches were observed after the axon passed through the region occupied by the terminals of RoP and were confined to the most medial layers of muscle fibers. Thus, although the arbors of RoP and $\mathrm{CaP}$ appear to overlap in Figure 5 , they actually projected to muscle fibers in different layers; there was no evidence that they innervated the same fibers. No branches of the $\mathrm{CaP}$ motoneuron were seen in the dorsal part of the ventral muscle or ventral to the ribs ( 15 axons, 8 animals). The field of innervation (Fig. 5) was consistent from animal to animal, with essentially all the fibers in the ventral $61 \pm 6 \%$ of the muscle between the horizontal septum and the end of the ribs covered by terminals. Within this region, individual fibers received multiple contacts distributed along their full length.
Secondary motoneuron axonal arbors

The arbors of secondary motoneurons varied considerably, although they were generally smaller than those of primary motoneurons. Secondary motoneurons often terminated on only a subset of muscle fibers within their field of innervation. The arbor of a secondary motoneuron is shown in the segments on the right side of Figure 5. This particular axon had branches that crossed the caudal myoseptum and terminated on muscle fibers in the adjacent segment, although many secondary motoneurons did not. This example also illustrates the general finding that secondary motoneurons usually had fewer terminals on each fiber than primary motoneurons.

\section{Pattern of innervation}

\section{Polyneuronal innervation of muscle fibers}

Most muscle fibers receive input from more than one motoneuron. This was observed by reducing the amplitude of evoked EPPs, with low-calcium saline, to a level that was subthreshold for activation of muscle action potentials. In this reduced $\mathrm{Ca}^{2+}$ saline, graded stimulation of the spinal nerve produced multiple EPPs in individual muscle fibers. An example of a fiber that had 3 EPPs is shown in Figure 6. At low stimulus strength (Fig. 6, bottom trace) a single EPP was evoked. Raising the stimulus strength evoked a second EPP, which was seen to summate with the lower threshold input (Fig. 6, middle trace). Stronger stimulation evoked a third input that summed with the first 2 (Fig. 6 , top trace). This third input had a distinctly larger amplitude and shorter latency than the other 2 inputs. Such amplitude and latency differences were found consistently (as described below).

These multiple EPPs could be due to electrical coupling between adjacent muscle fibers, which has been demonstrated in a number of developing neuromuscular systems (Blackshaw and Warner, 1976; Dennis, 1975). To test this possibility, simultaneous intracellular recordings from adjacent or nearby muscle fibers (53 pairs, 3 animals) were obtained with 2 microelectrodes. Large EPPs recorded in one fiber were not necessarily recorded in the other, even though multiple EPPs were present. Furthermore, depolarization (to a level equivalent to the EPP amplitude, $10-20 \mathrm{mV}$ ) of one fiber by injection of current through the recording electrode never produced a measurable potential change in the other. Thus, the multiple EPPs are not due to electrical coupling potentials from inputs to adjacent fibers; most probably they represent inputs from multiple motor axons.

Multiple EPPs could also be due to branching of individual motor axons proximal to the site of stimulation and failure of the antidromic action potential at the branch points. In such a case, axons might act independently even though they were branches of the same motoncuron. To test this possibility, the axons were stimulated before they entered the ventral root (presumably proximal to all branch points) by injecting current through a wire that had been threaded down the inside of the spinal cord. All branches of a motor axon should be activated by this procedure, thus reducing the number of inputs per muscle fiber if branching is an explanation for multiple inputs. In the 3 animals tested, equal numbers of EPPs were elicited in any given muscle fiber by graded stimulation proximal to the ventral root and by graded en passant stimulation of the spinal nerve more distally. This suggests that the multiple EPPs are produced by separate motoneurons and that the muscle fibers are polyneuronally innervated in addition to being multiterminally innervated as described above. Most of the muscle fibers $(82 \%)$ received inputs from 2 or 3 motoneurons, while very few (13\%) fibers received input from only a single motoneuron (Fig. 7).

\section{Muscle fibers receive input from a single primary motoneuron} Muscle fibers receive a consistent pattern of innervation. Typically they received inputs from one short-latency (fast-con- 

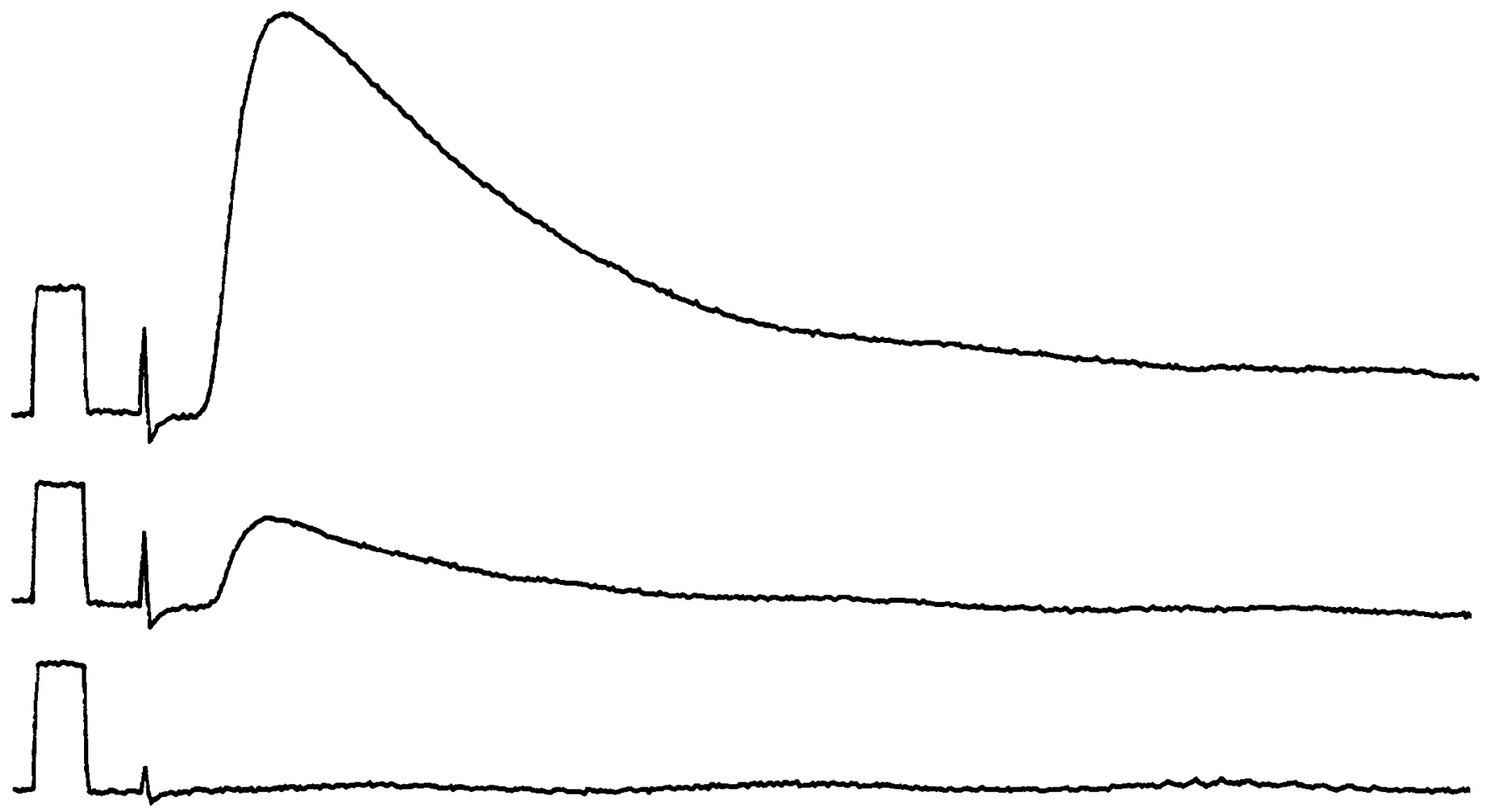

Figure 11. Segmental specificity of innervation. EPPs recorded from a muscle fiber in segment 11 after stimulation of the spinal nerve in scgment 11 (top trace), segment 12 (middle trace), and segment 13 (bottom trace). All traces show responses to maximal stimulation. Input from segment 11 (top trace) included 2 EPPs that could be distinguished by varying the amplitude of the stimulus. The input from segment 12 (middle trace) came from a single axon, as evidenced by its single amplitude, and no inputs from segment 13 (bottom trace) were recorded even though these segments contained polyneuronally innervated fibers. Resting potential, $-82 \mathrm{mV}$; calibration, $5 \mathrm{mV}$ and $2 \mathrm{msec}$.

ducting) axon and several longer latency (slower conducting) axons. Moreover, the short-latency axon usually produced the largest amplitude EPP. This is illustrated in Figure 6 which shows a fiber that received a large EPP $(13 \mathrm{mV})$ with a $1.9 \mathrm{msec}$ latency following the stimulus (top trace), and smaller EPPs (1.6 $\mathrm{mV}$ and $1.1 \mathrm{mV}$ ) with 2.6 and $2.8 \mathrm{msec}$ latencies (middle and bottom traces, respectively). On average, the shortest latency EPP in 93 ventral muscle fibers ( 8 animals) was $1.8 \pm 0.2 \mathrm{msec}$; this was significantly shorter than the second input in these same fibers, which occurred $2.3 \pm 0.2 \mathrm{msec}$ after the stimulus. A third EPP was recorded in 43 of these fibers at an average latency of $2.4 \pm 0.3 \mathrm{msec}$, and 11 fibers had a fourth input at $2.7 \pm 0.3$ $\mathrm{msec}$. A similar pattern of innervation was found in the dorsal muscle. Nearly all the fibers received inputs from 1 short-latency axon in the dorsal nerve $(2.1 \pm 0.2 \mathrm{msec}, 33$ fibers in 4 animals) and several longer latency axons (second EPP occurred at an average latency of $2.6 \pm 0.2 \mathrm{msec}$ in 33 fibers, third EPP occurred at $2.7 \pm 0.2 \mathrm{msec}, 11$ fibers).

The short-latency, large-amplitude EPP probably corresponds to input from a primary motoneuron since these neurons have the largest diameter and presumably fastest conducting axons. This notion was tested for the CaP motoneuron by correlating the short-latency, large-amplitude EPP elicited by stimulation of the ventral root with the EPP elicited by intracellular stimulation of the $\mathrm{CaP}$ axon. This is illustrated in Figure 8 with a muscle fiber that received input from 3 axons (top panel). One of these inputs had a significantly shorter latency and larger amplitude than the other 2 (top trace of top panel). Its amplitude (middle panel) was the same as the amplitude of the EPP (bottom panel) evoked in this muscle fiber by direct stimulation of the $\mathrm{CaP}$ axon and much larger than the amplitudes of the other 2 inputs. Thus, in this and in each case examined (14 muscle fibers, 2 animals), the axon of the primary motoneuron produced the shortest latency EPP. Moreover, the short-latency EPP usu- ally had a larger amplitude than the slower inputs (Fig. 9), consistent with the larger number of terminals from the primary motoneurons on each muscle fiber (Fig. 5).

\section{Primary motoneurons have nonoverlapping fields}

The peripheral fields of individual motoneurons were mapped physiologically (Fig. 10). We obtained simultaneous recordings from pairs of muscle fibers and determined which EPPs in each pair were produced by the same motoneuron by measuring the threshold of each EPP. The field of an individual motoneuron was mapped by moving one electrode from fiber to fiber, while holding the other in a single fiber. In all cases (4 segments, 4 animals), the axon with the short-latency EPP that innervated the ventral part of the segment (presumably the CaP motoneuron) had a large field that included nearly all of the fibers in the ventral part of the ventral muscle (Fig. 5). In no case did the field of this neuron extend across a segment border or into the dorsal muscle. Similarly, the fields of RoP and MiP were confined to the segment containing their cell bodies and included a set of contiguous muscle fibcrs. The fields of secondary motor axons varied in size and in some cases ( 2 axons, 8 animals) extended across segment borders. In general, the fields of all axons were restricted to either dorsal or ventral muscle: Of 63 fiber pairs examined in 8 animals, only a single axon was found that innervated fibers in both regions.

\section{Intersegmental organization of innervation}

Muscle fibers are innervated in a segmentally specific manner. This was observed by recording from a given muscle fiber while stimulating the spinal nerves from adjacent segments. Figure 11 shows records from a fiber that received inputs from its own segment (upper trace), an input from the next most caudal segment (middle trace), and no inputs from the next most rostral segment or from subadjacent (one segment removed) segments 
(lower trace). In $8 \%$ of 193 fibers (5 animals), there was a single input (see legend of Fig. 11) from an adjacent segment, and no cases of more than one input from this segment were observed. Furthermore, no muscle fibers were found to receive innervation from subadjacent segments.

\section{Discussion}

\section{Identified motoneurons}

The experiments described here have demonstrated that individual motoneurons can be recognized reproducibly in each spinal segment in the trunk region of zebrafish. We find that these neurons are uniquely identifiable by several criteria. First, their cell bodies and axons are easily distinguishable as the largest motoneurons. Second, their cell bodies occupy unique positions within the spinal cord, being farther dorsal and medial than other motoneurons. Third, their axons consistently run in particular nerves, and, fourth, they innervate specific fields of muscle fibers.

Based on these criteria, we have distinguished 3 primary motoneurons in each segment on each side of the spinal cord. The most rostral motoneuron (RoP) innervates fibers in the dorsal part of the ventral muscle of its own segment. The second motoneuron (MiP), located in an intermediate region of each spinal segment, exclusively innervates fibers in the dorsal muscle of its own segment. The most caudal of the $3(\mathrm{CaP})$ is reproducibly located near the level of the ventral root. Its axon crosses the horizontal septum and the dorsal part of the ventral muscle without branching. It specifically innervates nearly all the fibers in the ventral two-thirds of the ventral muscle of its own segment. We have also recently identified these 3 unique motoneurons in embryonic zebrafish (Eisen et al., 1986; Myers et al., 1986).

Collectively, these 3 motoneurons correspond in size to the primary motoneurons described in larval Xenopus (Blight, 1978) and in larval zebrafish (Myers, 1983, 1985). The smaller motoneurons, characteristically found more ventrally and laterally in the spinal cord, correspond to the secondary motoneurons of these earlier studies. The secondary motoneurons also are distinguished from the primary motoneurons by their smaller axons and their characteristically smaller fields. The number of axons in the ventral root is small and remarkably constant from animal to animal, suggesting that the total number of motoneurons may be tightly regulated. Until detailed correlations of the cell-body positions and peripheral fields of individual secondary motoneurons are obtained, it will not be clear whether these neurons are also uniquely identifiable.

\section{Polyneuronal and multiterminal innervation of muscle fibers}

Zebrafish white muscle fibers are polyneuronally innervated. This distinguishes them from many other adult vertebrates, most notably mammals, in which each skeletal muscle fiber is innervated by a single motoneuron. Additionally, zebrafish fibers are polyinnervated by only a few motoneurons; this is in contrast to other fish (Bone, 1978; Ono, 1983), most notably some marine teleosts, in which polyinnervation by as many as 22 motoneurons has been reported (Hudson, 1969). In these species, unlike the zebrafish, significant numbers of inputs come from motoneurons located in subadjacent spinal segments. Moreover, these previous studies concluded that polyinnervation occurs in the absence of multiterminal innervation (Hudson, 1969), while motor axons in the zebrafish clearly make multiple terminals on muscle fibers. Recent observations in garter snakes (Lichtman et al., 1985) have shown that polyneuronally innervated fibers lack muscle action potential activity. This differs in the zebrafish, since EPPs generate action potentials in the majority of muscle fibers even though most of these fibers are polyneuronally innervated.

\section{Cell-specific fields of innervation}

The 3 primary motoneurons identified in this study are sharply restricted in their patterns of innervation. With no exceptions, anatomical and physiological projections of these neurons were confined to the segment containing their cell bodies. Moreover, comparison of the innervation patterns demonstrates that these neurons innervate mutually exclusive fields of muscle fibers within their own segment. The origin of this specificity is unclear. It is unlikely that axons are confined to their own segment by physical barriers in the myosepta, since the axons of some secondary motoneurons cross these segment borders (Fig. 5). Similarly, the specificity cannot be due to a mechanism of general competition among all motoneurons, as found in mammals (Van Essen, 1982), since the majority of muscle fibers remain polyncuronally inncrvated (Figs. 6,7 ) as late as 2 years into adulthood. On the other hand, it could be that the primary motoneurons compete among themselves for exclusive innervation of a particular field while sharing that field with one or more secondary motoneurons. This would suggest a finer level of competition than previously described, since motoneurons would compete with members of their own class while sharing targets with members of other classes. Finally, the specificity of innervation may be due to precise target selection during initial innervation. Such selective synapse formation seems likely, since observations of embryonic zebrafish (Eisen et al., 1986; Myers et al., 1986) suggest that the axons of the primary motoneurons initially grow to regions that correspond to their adult fields with no obvious overlap or retraction of inappropriately projecting processes.

\section{References}

Alexander, R. M. (1969) The orientation of muscle fibers in the myomers of fishes. J. Mar. Biol. Assn. U.K. 49: 263-290.

Blackshaw, S. E., and A. E. Warner (1976) Low resistance junctions between mesoderm cells during development of trunk muscles. J. Physiol. (Lond.) 255: 209-230.

Blight, A. R. (1978) Golgi-staining of "primary" and "secondary" motoneurons in the developing spinal cord of an amphibian. J. Comp. Neurol. 180: 679-690.

Bone, Q. (1978) Locomotor muscle. In Fish Physiology, W. S. Hoar and D. J. Randall, eds., pp. 361-424, Academic, New York.

Burke, R. E., D. N. Levine, P. Tsairis, and F. E. Zajac III (1973) Physiological types and histochemical profiles in motor units of the cat gastrocnemius. J. Physiol. (Lond.) 234: 723-748.

del Castillo, J., and G. Escalona de Motta (1978) A new method for excitation-contraction uncoupling in frog skeletal muscle. J. Cell Biol. 78: 782-784.

Dennis, M. (1975) Physiological properties of junctions between nerve and muscle developing during salamander limb regeneration. J. Physiol. (Lond.) 244: 393-408.

Eisen, J. S., P. Z. Myers, and M. Westerfield (1986) Pathway selection by growth cones of identified motoneurons in live zebrafish embryos. Nature 320: 269-271.

Faber, D. S., and H. Korn (1978) Electrophysiology of the Mauthner cell in fish and amphibians. In Neurobiology of the Mauthner Cell, D. S. Faber and H. Korn, eds., Raven, New York.

Hoyle, G. (1983) Muscles and Their Neural Control, pp. 263-311, Wiley-Interscience, New York.

Hudson, R. C. L. (1969) Polyneuronal innervation of the fast muscles of the marine teleost Cottus scorpius L. J. Exp. Biol. 50: 47-67.

Kimmel, C. B. (1982) Reticulospinal and vestibulospinal neurons in the young larva of a teleost fish, Brachydanio rerio. Prog. Brain Res. 57: 1-23.

Landmesser, L. T. (1980) The generation of neuromuscular specificity. Annu. Rev. Neurosci. 3: 279-302.

Lichtman, J. W. (1977) The reorganization of synaptic connexions in the rat submandibular ganglion during post-natal development. J. Physiol. (Lond.) 273: 155-177.

Lichtman, J. W., R. S. Wilkinson, and M. M. Rich (1985) Multiple innervation of tonic endplates revealed by activity-dependent uptake of fluorescent probes. Nature 314: 357-359. 
Metcalfe, W. K., C. B. Kimmel, and E. Schabtach (1985) Anatomy of the posterior lateral line system in young larvae of the zebrafish. J. Comp. Neurol. 233: 377-389.

Myers, P.Z. (1983) Morphology and development of motoneurons in the zebrafish spinal cord. Soc. Neurosci. Abstr. 9: 848 .

Myers, P. Z. (1985) Spinal motoneurons of the larval zebrafish. J. Comp. Neurol. 236: 555-561.

Myers, P. Z., J. S. Eisen, and M. Westerfield (1986) Development and axonal outgrowth of identified motoneurons in the zebrafish. J. Neurosci. 6: 2278-2289.

Ono, R. D. (1983) Dual motor innervation in the axial musculature of fishes. J. Fish Biol. 22: 395-408.

van Raamsdonk, W., A. van der Stelt, P. C. Diegenbach, W. van de Berg, H. de Bruyn, J. van Dijk, and P. Mijzen (1974) Differentiation of the musculature of the teleost Brachydanio rerio. I. Myotome shape and movements in the embryo. Z. Anat. Entwickl. Gesch. 145: 321342.

Romer, A. S. (1962) The Vertebrate Body, pp. 255-258, Saunders, Philadelphia.
Rovainen, C. M. (1978) Muller cell, "Mauthner cells" and other identified reticulospinal neurons in the lamprey. In Neurobiology of the Mauthner Cell, D. S. Faber and H. Korn, eds., Raven, New York.

Van Essen, D. C. (1982) Neuromuscular synapse elimination. In Neuronal Development, N. C. Spitzer, ed., pp. 333-376, Plenum, New York.

Waterman, R. E. (1969) Development of the lateral musculature in the teleost, Brachydanio rerio: A fine structural study. Am. J. Anat. 125: 457-494.

Westerfield, M., and J. S. Eisen (1985) The growth of motor axons in the spinal cord of Xenopus embryos. Dev. Biol. 109: 96-101.

Westerfield, M., P. Z. Myers, and J. S. Eisen (1984) Polyneuronal and intersegmental innervation of body muscles in the zebrafish. Soc. Neurosci. Abstr. 10: 371

Willison, R. G. (1980) Arrangement of muscle fibers of a single motor unit in mammalian muscles. Muscle Nerve 3: 360-361. 